\title{
REFLECTIONS FROM A FOUNDING EDITOR
}

\author{
EDWARD M. BENNETT \\ Department of Psychology, Wilfrid Laurier University
}

\begin{abstract}
As a founding editor of the Canadian Journal of Community Mental Health (CJCMH), I am very excited to witness this 25 th anniversary and believe that there is cause for congratulations and celebration.

The 25-year journey of CJCMH has, in my opinion, been an important one. Our founding vision and mission statement was ambitious. Given that the dominant social paradigm at the time was focused on individuals separate from their social environments, disease-oriented, and dominated by the medical establishment, it was a big step to create an inter-disciplinary journal of community mental health focused on the overarching themes of the "promotion of mental health and the prevention of mental health problems in community settings." It is gratifying to note that Fortin-Pellerin, PouliotLapointe, Thibodeau, and Gagné's content analysis and Nelson's commentary confirm that many of the key elements of the founding vision and mission statement have been actualized. It also is wonderful to see within the anlaysis evidence of the journal's social justice values.
\end{abstract}

\section{BEFORE THE BEGINNING}

Given that we had no articles, no subscribers, and no funding in-hand when we announced the launch of CJCMH, it is hardly surprising that we experienced a sizeable amount of trepidation. With only an embryonic inter-disciplinary editorial board in place and a recently declared moratorium on the funding of new scholarly journals by the Social Sciences and Humanities Research Council of Canada (SSHRC), we found it difficult to get things started. The tasks of soliciting appropriate, highquality publication material, building a base of subscribers, finding sufficient funding for the project, and identifying and developing an inter-disciplinary editorial team all posed significant challenges. I am grateful to my colleagues on that founding editorial team: Barry Trute, Maurice Payette, David Bakan, and Alex Porteus. Our combined efforts in creating CJCMH, though fraught with challenges, were both fun and purposeful. I am also grateful to the senior editors and editorial board members who came after us; the journal's success in realizing its goals is a tribute to all of them.

\section{SPECIAL ISSUES AND SUPPLEMENTS}

I believe that the special issues and supplements published over the past 25 years deserve particular attention. These issues have, I think, been vital to the realization of CJCMH's overarching goals. They have complemented the journal's regular issues and made it possible for editorial teams to give special focus to critical concerns in the field of contemporary community mental health. Further, they have facilitated the sharing of information in highly diverse areas of investigation and enhanced the creation and codification of elements of valid and reliable knowledge about phenomena pertinent to 
the mental well-being of Canadians. The journal's first special issue-“Community Psychology in Canada," published in September 1982-is an excellent example and represents an important milestone in community psychology in Canada. In short, I believe that special issues and supplements can have a transformative influence, and can represent a special form of leadership in the realization of community mental health agendas.

\section{FUTURE DIRECTIONS}

The fact that the journal's mission statement has endured the test of time and has remained unchanged since 1982 is both interesting and challenging. Given the changes in zeitgeist which have occurred over the past 25 years, should the mission statement be changed to include other priority areas? What do these changes mean for the foci and roles of CJCMH?

I believe that it is time to consider expanding our areas of priority to include the relationship between community mental health and the issues of: (a) globalization, (b) innovation, (c) social justice and economic equality, and (d) spiritual values. Although the first two of these themes have been the focus of past special issues, I suggest that, particularly in the current global context, all four warrant priority attention because of their profound importance to community mental health and wellness in Canada. 